\title{
PENGARUH PUKAN PLUS DAN PUPUK ANORGANIK TERHADAP HASIL JAGUNG MANIS DAN NUTRISI JERAMI SEBAGAI PAKAN TERNAK
}

\author{
Dwi Retno Lukiwati dan Yafizham (alm.) \\ Jurusan Pertanian, Fakultas Peternakan dan Pertanian, Universitas Diponegoro \\ Kampus Undip Tembalang, Semarang \\ e-mail:drlukiwati_07@yahoo.com
}

\begin{abstract}
ABSTRAK
Jagung manis (Zea mays saccharata) sensitif terhadap defisiensi nitrogen dan fosfor pada media tumbuhnya, dan masalah ini dapat diatasi dengan pemanfaatan pupuk kandang (pukan) diperkaya NP-organik yang kemudian disebut sebagai pukan plus. Tujuan penelitian adalah untuk mengkaji pengaruh pukan plus dan pukan organik terhadap hasil jagung manis dan nutrisi jerami sebagai pakan ternak. Penelitian lapang di Kabupaten Grobogan Jawa Tengah menggunakan rancangan acak kelompok dengan 7 perlakuan dan 4 ulangan sebagai kelompok. Dosis pupuk N, P dan K masing-masing $200 \mathrm{~kg} \mathrm{~N} / \mathrm{ha}, 150 \mathrm{P}_{2} \mathrm{O}_{5} / \mathrm{ha}$ dan 150 $\mathrm{kg} \mathrm{K}_{2} \mathrm{O}$ /ha dengan menggunakan ZA, N-lamtoro, P-batuan fosfat dan TSP serta KCl. Pupuk kandang (sapi, kambing, ayam) maupun pukan diperkaya NP-organik masing-masing dengan dosis 20 ton/ha. Perlakuan yang diberikan adalah T1 (ZA+TSP), T2 (pukan sapi+ZA+TSP), T3 (pukan kambing+ZA+TSP), T4 (pukan ayam+ZA+TSP), T5 (pukan sapi plus), T6 (pukan kambing plus), T7 (pukan ayam plus). Panen jagung manis pada umur 70 hari setelah tanam, kemudian tongkol berkelobot maupun tanpa kelobot ditimbang, demikian juga jeraminya dan selanjutnya dianalisis nutrisinya. Hasil penelitian menunjukkan bahwa perlakuan pemupukan yang diberikan nyata berpengaruh terhadap serapan nitrogen tetapi tidak terhadap hasil tongkol maupun jerami serta serapan P. Hasil uji DMRT menunjukkan bahwa pukan kambing plus dan pukan ayam plus menghasilkan serapan N nyata lebih tinggi dibanding pemupukan ZA+TSP. Disimpulkan bahwa pukan plus (pupuk kandang diperkaya NP-organik) dapat menggantikan pupuk anorganik (ZA, TSP).
\end{abstract}

Kata kunci : batuan fosfat, jerami, Leucaena leucocephala, pupuk kandang, Zea mays saccharata

\section{EFFECT OF MANURE PLUS AND INORGANIC FERTILIZER ON SWEET CORN YIELD AND NUTRITION OF STOVER AS LIVESTOCK FEED}

\begin{abstract}
Sweet corn (Zea mays saccharata) sensitive to $\mathrm{N}$ and $\mathrm{P}$ deficiency, and organic-NP enriched manure (manure plus) to become the solution. The objective of the research was to evaluate the influence of organicNP enriched manure and manure+inorganic and inorganic fertilizer on sweet corn yield and stover yield and NP uptake. A field experiment in Grobogan Distric-Central Java with RCBD and 7 treatments and four replicates was conducted in Grobogan district. Level of P (RP, TSP), N (ZA, N-Leucaena leucocephala), and $\mathrm{K}(\mathrm{KCl})$ was $200 \mathrm{~kg} \mathrm{~N} / \mathrm{ha}, 150 \mathrm{P}_{2} \mathrm{O}_{5} /$ ha dan $150 \mathrm{~kg} \mathrm{~K}{ }_{2} \mathrm{O} /$ ha, respectively. All of manure (cow, goat, poultry) application at $20 \mathrm{t} / \mathrm{ha}$, and manure plus. The treatments were T1 (ZA+TSP), T2 (cow manure+ZA+TSP), T3 (goat manure +ZA+TSP), T4 (poultry manure+ZA+ TSP), T5 (cow manure plus), T6 (goat manure plus), $\mathrm{T}_{7}$ (poultry manure plus). Sweet corn was harvested at 70 days after planting, the stover was cut and measured for nutritive value. The result showed that the treatment significantly affected to nitrogen uptake, but not for sweet corn yield and fresh stover and dry mater stover and phosphorus uptake. The result of DMRT showed that effect of goat manure plus and poultry manure plus were significantly higher compared to ZA+TSP treatment. Conclusion, manure plus (NP-organic enriched manure) replaces ZA+TSP as inorganic fertilizer.
\end{abstract}

Keywords : rock phosphate, stover, Leucaena leucocephala, manure, Zea mays saccharata

\section{PENDAHULUAN}

Produksi ternak ruminansia dipengaruhi oleh kuantitas maupun kualitas serta kontinyuitas pakan yang diberikan. Namun demikian, lebih dari 80\% ternak dipelihara hanya sebagai 'sambilan' atau bukan usaha utama bagi petani-peternak yang juga bercocok tanam dalam sistem integrasi tanamanternak (SITT) (Lukiwati dan Muryani, 2006). Integrasi tanaman-ternak misalnya jagung dan sapi, 
termasuk salah satu sistem pertanian terpadu yang dikembangkan di Indonesia dengan konsep 'zero waste' atau sistem pertanian bebas limbah, karena limbah peternakan dimanfaatkan untuk pupuk kandang (pukan), sedangkan limbah tanaman pangan (jerami) sebagai pakan ternak. Penerapan SITT memberikan keuntungan dari sisi ekonomi, maupun pemanfaatan sumberdaya lebih optimal (Syamsu et al., 2013). Selanjutnya Abdullah dan Syamsu (2015) menjelaskan bahwa nilai indeks keberlanjutan adopsi teknologi pengolahan limbah peternakan sebagai pupuk kandang dalam SITT berdasarkan dimensi teknologi termasuk cukup berkelanjutan. Dengan inovasi teknologi pembuatan pukan, dapat berpotensi sebagai pengganti pupuk anorganik (Lukiwati et al., 2010).

Pupuk kandang mengandung unsur hara makro maupun mikro, namun kadarnya sangat rendah sehingga perlu ditingkatkan kualitasnya dengan penambahan P-batuan fosfat (P-BP) (Lukiwati et al., 2014, Qureshi et al., 2014) maupun dengan N-organik misalnya N-Gliricidea sepium (Shridar et al., 2001,: Widjajanto, 2013). Disamping itu, pukan juga dapat diperkaya dengan NP-organik (N-Gliricidea sepium dan P-BP, P-guano) (Lukiwati et al., 2018; Lukiwati et al., 2019) untuk menekan kebergantungan pada penggunaan pupuk anorganik. Pupuk anorganik seperti TSP mudah larut dalam air, sedangkan BP larut dalam asam (Dierolf et al., 2001), oleh karena itu produksi jagung lebih tinggi dengan pemupukan TSP dibanding BP (Lukiwati, 2002). Selama ini petani sangat bergantung pada pupuk TSP, urea maupun ZA di setiap musim tanam, yang kadang langka tersedia serta mahal harganya dan tidak ramah lingkungan. Oleh karena itu, pupuk kandang diperkaya fosfat alam maupun NP organik yang kemudian disebut 'pukan plus' dapat dimanfaatkan untuk mengatasi masalah tersebut.

Pukan yang diperkaya BP mampu meningkatkan ketersediaan P-BP dibanding ketika pukan dan BP diberikan masing-masing ke dalam tanah (Lukiwati et al., 2010, Imran et al., 2011). Hal ini disebabkan karena fosfat alam akan meningkat ketersediaannya dengan adanya asam-asam organik yang dihasilkan selama proses dekomposisi pukan diperkaya BP (Singh dan Reddy, 2011). Pukan diperkaya NPorganik mampu menghasilkan tongkol jagung pulut (Zea mays ceratina L.) dan produksi jerami setara dengan pemupukan TSP+ZA (Lukiwati et al., 2019). Pukan diperkaya NP-organik (N-Gliricidea sepium, P-BP) juga mampu menghasilkan nutrisi jerami jagung manis (Zea mays saccharata) setara dengan pemupukan TSP+ZA (Lukiwati et al., 2018). Pukan diperkaya P-BP maupun P-guano mampu menghasilkan tongkol jagung pulut dan produksi bahan kering serta nutrisi jerami setara dengan TSP (Lukiwati et al., 2018). Berdasarkan uraian tersebut, akan dibahas dalam artikel ini mengenai pengaruh berbagai jenis pukan (sapi, kambing, ayam) dan pukan (sapi, kambing, ayam) diperkaya NP-organik (N-Leucaena leucocephala, $\mathrm{P}-\mathrm{BP}$ ) dan pemupukan anorganik terhadap hasil jagung manis, jerami dan serapan nutrisi jerami.

\section{MATERI DAN METODE}

Penelitian lapang telah dilaksanakan di Kabupaten Grobogan, selama 70 hari, menggunakan tanah tidak subur (berdasarkan hasil analisis tanah). Materi penelitian yang digunakan adalah benih jagung manis, pupuk amonium sulfat (ZA), TSP, pupuk dasar KCl dan pupuk kandang (sapi, kambing, ayam), pukan plus (sapi, kambing, ayam), batuan fosfat, dan legum Leucaena leucocephala (lamtoro).

Pembuatan pukan (sapi, kambing, ayam) masingmasing dengan dosis 20 ton/ha ditambahkan tetes (molase) dan EM-4 kemudian diperam selama 2 bulan. Demikian pula pukan plus (sapi, kambing, ayam) yaitu pukan diperkaya dengan N-lamtoro $(200 \mathrm{~kg}$ $\mathrm{N} /$ ha) dan P-BP (150 $\mathrm{P}_{2} \mathrm{O}_{5} /$ ha) setara dengan P-TSP dan N-ZA. Pupuk $\mathrm{KCl}$ (150 $\mathrm{kg} \mathrm{K}_{2} \mathrm{O} / \mathrm{ha}$ ) diberikan sebagai pupuk dasar. Analisis kimia tanah dan pukan maupun pukan plus dilakukan sebelum penelitian dilaksanakan. Perlakuan pemupukan yang diberikan adalah T1 (ZA+TSP), T2 (pukan sapi+ZA+TSP), T3 (pukan kambing+ZA+TSP), T4 (pukan ayam+ZA+TSP, T5 (pukan sapi plus), T6 (pukan kambing plus), T7 (pukan ayam plus). Rancangan percobaan yang digunakan adalah rancangan acak kelompok dengan 7 perlakuan dan 4 kali ulangan sebagai kelompok, sehingga terdapat 28 petak percobaan, masing-masing berukuran $2 \mathrm{~m} \times 3,2 \mathrm{~m}$.

\section{Pelaksanaan Penelitian}

Media tanam disiapkan sebanyak 28 petak, dilanjutkan pemupukan pukan dan pukan plus sesuai perlakuan diberikan 3 hari sebelum tanam benih jagung. Jagung ditanam secara tugal, masingmasing dua benih tiap lubang tanam dengan jarak $40 \mathrm{~cm} \times 40 \mathrm{~cm}$ sehingga terdapat 40 lubang tanam tiap petak. Ketika tanaman jagung berumur 7 hari setelah tanam (HST), dilakukan pemupukan TSP dan ZA sesuai perlakuan serta $\mathrm{KCl}$ sebagai pupuk dasar. Perawatan tanaman dilakukan meliputi penyiraman apabila diperlukan, pengendalian hama dengan pemberian insektisida furadan ketika mulai muncul 3 helai daun, dan pengendalian gulma.

Panen jagung dilakukan pada umur 70 hari setelah tanam (HST), dilanjutkan penimbangan tongkol jagung secara sampling tiap petak penelitian. 
Penimbangan jerami dilanjutkan analisis kadar air untuk mendapatkan data kadar bahan kering, kemudian dilakukan analisis nutrisi jerami jagung untuk memperoleh data serapan $\mathrm{N}(\% \mathrm{~N} \times$ produksi $\mathrm{BK})$ dan serapan $\mathrm{P}(\% \mathrm{P} \times$ produksi $\mathrm{BK})$. Data hasil penelitian ditabulasikan dan dilakukan analisis ragam untuk mengetahui pengaruh perlakuan, dilanjutkan uji DMRT untuk mengetahui perbedaan antar perlakuan terhadap parameter yang diamati.

\section{HASIL DAN PEMBAHASAN}

\section{Hasil Analisis Tanah dan Pupuk Kandang}

Hasil analisis kimia tanah tempat penelitian termasuk rendah kadar $\mathrm{N}$ dan $\mathrm{P}$ masing-masing berkisar 0,24-0,28\% dan 4,90-5,47 ppm. Sedangkan kadar N, P dan K pupuk kandang (pukan) sapi, kambing dan ayam lebih rendah dibanding pukan plus (sapi, kambing dan ayam). Namun nutrisi pukan (kambing, ayam) lebih tinggi dibanding pukan sapi, demikian pula nutrisi pukan plus (kambing, ayam) lebih tinggi dibanding pukan sapi plus (data tidak ditampilkan). Secara keseluruhan rata-rata kadar N dan P pukan tersebut masing-masing sekitar 2,18\% dan $2.38 \%$. Kualitas pupuk kandang tersebut masih lebih tinggi dibanding hasil penelitian Soelaeman (2008) yaitu kadar N dan P masing-masing 0,55\% dan $0,12 \%$. Hal ini disebabkan karena adanya inokulasi biodekomposer EM4 dalam proses pembuatan pukan yang berperan langsung dalam mempercepat proses dekomposisi, mobilisasi dan mineralisasi nutrisi (Manoharachary et al. 2005).

\section{Berat Tongkol Berkelobot Dan Tanpa Kelobot Serta Serapan Nutrisi}

Hasil analisis ragam menunjukkan bahwa perlakuan pemupukan yang diberikan berpengaruh tidak nyata terhadap berat tongkol berkelobot maupun tanpa kelobot (Tabel 1). Demikian pula, perlakuan pemupukan yang diberikan tidak berpengaruh nyata terhadap berat segar jerami maupun bahan kering jerami (Tabel 2). Hal ini disebabkan karena semua perlakuan pemupukan yang diberikan menggunakan $\mathrm{N}$, $\mathrm{P}$ dan $\mathrm{K}$ dengan dosis yang sama, masing-masing $200 \mathrm{~kg} \mathrm{~N} / \mathrm{ha}, 150 \mathrm{~kg} \mathrm{P}_{2} \mathrm{O}_{5} / \mathrm{ha}$ dan $150 \mathrm{~kg} \mathrm{~K} \mathrm{O}_{2} \mathrm{O}$ ha. Diduga nilai nutrisi perlakuan pemupukan anorganik (T1), pukan+anorganik (T2, T3, T4) dan pukan plus ( $55, \mathrm{~T} 6, \mathrm{~T} 7)$ memberikan pengaruh yang sama terhadap hasil tongkol berkelobot maupun tanpa kelobot, dan berat jerami segar maupun bahan kering plus ( $\left.\mathrm{T}_{5}, \mathrm{~T} 6, \mathrm{~T} 7\right)$ memberikan pengaruh yang sama terhadap hasil tongkol berkelobot maupun tanpa kelobot, dan berat jerami segar maupun bahan kering jerami. Hasil yang sama dilaporkan oleh Ramilison (2001), bahwa efektivitas pupuk P dapat ditingkatkan dengan adanya pupuk NK. Produksi jerami jagung bergantung pada jenis pemupukan yang diberikan (Wireko-Manu dan Amamoo, 2017, Lukiwati et al., 2018).

Tabel 1. Berat Tongkol Berklobot dan Tanpa Kelobot

\begin{tabular}{lcc}
\hline \multicolumn{1}{c}{ Perlakuan } & $\begin{array}{c}\text { Tongkol berkelobot } \\
\text { (g/tongkol) }\end{array}$ & $\begin{array}{c}\text { Tongkol tanpa } \\
\text { kelobot (g/tongkol) }\end{array}$ \\
\hline ZA+TSP & $253,13 \pm 19,16$ & $155,63 \pm 19,40$ \\
Pukan sapi+ZA+TSP & $285,63 \pm 10,23$ & $180,00 \pm 8,72$ \\
Pukan kambing+ZA+TSP & $280,81 \pm 24,61$ & $185,81 \pm 19,69$ \\
Pukan ayam+ZA+TSP & $288,13 \pm 52,71$ & $175,00 \pm 34,46$ \\
Pukan sapi plus & $275,00 \pm 7,57$ & $186,88 \pm 6,32$ \\
Pukan kambing plus & $243,13 \pm 30,44$ & $146,25 \pm 20,63$ \\
Pukan ayam plus & $267,50 \pm 10,36$ & $171,25 \pm 8,69$ \\
\hline
\end{tabular}

Tabel 2. Berat Segar dan Bahan Kering Jerami Jagung Manis

\begin{tabular}{lcc}
\hline \multicolumn{1}{c}{ Perlakuan } & $\begin{array}{c}\text { Berat segar jerami } \\
(\mathrm{g} / \text { tanaman })\end{array}$ & $\begin{array}{c}\text { Hasil bahan kering } \\
(\mathrm{g} / \text { tanaman })\end{array}$ \\
\hline ZA+TSP & $366,25 \pm 20,25$ & $81,33 \pm 9,54$ \\
Pukan sapi+ZA+TSP & $391,25 \pm 27,49$ & $92,21 \pm 8,60$ \\
Pukan kambing+ZA+TSP & $394,69 \pm 33,25$ & $85,21 \pm 7,41$ \\
Pukan ayam+ZA+TSP & $407,50 \pm 35,69$ & $84,23 \pm 9,35$ \\
Pukan sapi plus & $373,44 \pm 22,90$ & $75,02 \pm 4,81$ \\
Pukan kambing plus & $405,94 \pm 11,47$ & $91,85 \pm 3,66$ \\
Pukan ayam plus & $371,88 \pm 20,24$ & $84,00 \pm 3,92$ \\
\hline
\end{tabular}

\section{Serapan nitrogen dan fosfor jerami}

Hasil analisis ragam menunjukkan bahwa perlakuan pemupukan yang diberikan berpengaruh nyata terhadap serapan nutrisi jerami jagung manis. Data Tabel 3 menunjukkan bahwa aplikasi pukan+anorganik ( $\left.\mathrm{T}_{2}, \mathrm{~T}_{3}, \mathrm{~T}_{4}\right)$ tidak berbeda nyata terhadap pukan plus ( $\left.\mathrm{T}_{4}, \mathrm{~T} 5, \mathrm{~T} 6\right)$ dalam menghasilkan serapan nitrogen. Namun aplikasi pukan kambing plus (T6) dan pukan ayam plus (T7) menghasilkan serapan nitrogen nyata lebih tinggi dibanding perlakuan pemupukan anorganik (TSP+ZA), sedangkan perlakuan pukan sapi plus tidak berbeda nyata terhadap pupuk anorganik. Perlakuan pemupukan yang diberikan menggunakan $\mathrm{N}, \mathrm{P}$ dan $\mathrm{K}$ dengan dosis yang sama, masing-masing $200 \mathrm{~kg}$ N/ha, 150 kg $\mathrm{P}_{2} \mathrm{O}_{5} /$ ha dan $150 \mathrm{~kg} \mathrm{~K} \mathrm{~K}_{2} \mathrm{O} / \mathrm{ha}$. Namun demikian, nilai nutrisi pukan kambing plus (T6) dan pukan ayam plus ( $\left.\mathrm{T}_{7}\right)$ lebih tinggi dibanding pukan sapi plus sehingga mampu meningkatkan serapan $\mathrm{N}$ nyata lebih tinggi dibanding pupuk anorganik (T1). Diduga pukan kambing plus dan pukan ayam plus mampu menyediakan unsur hara nitrogen lebih tinggi dibanding pupuk ZA+TSP sehingga serapan $\mathrm{N}$ lebih tinggi. Unsur hara nitrogen ekternal yang ditambahkan mampu mendukung ketersediaan $\mathrm{N}$ tanah sehingga menghasilkan serapan $\mathrm{N}$ lebih tinggi (Bhatt, 2012).

Perlakuan pemupukan yang diberikan menunjukkan perbedaan yang tidak nyata dalam menghasilkan serapan fosfor (Tabel 3). Perlakuan 
pemupukan yang diberikan menggunakan $\mathrm{N}, \mathrm{P}$ dan $\mathrm{K}$ dengan dosis yang sama, masing-masing $200 \mathrm{~kg} \mathrm{~N} / \mathrm{ha}, 150 \mathrm{~kg} \mathrm{P}_{2} \mathrm{O}_{5} /$ ha dan $150 \mathrm{~kg} \mathrm{~K} \mathrm{~K}_{2} \mathrm{O} / \mathrm{ha}$ berupa pupuk anorganik maupun organik. Hal ini disebabkan karena dalam pembuatan pukan maupun pukan plus, dilakukan inokulasi biodekomposer EM4 yang berperan langsung dalam mempercepat proses dekomposisi, mobilisasi dan mineralisasi nutrisi (Manoharachary et al., 2005), sehingga kadar $\mathrm{N}$ maupun $\mathrm{P}$ pukan maupun pukan plus lebih tinggi dibanding yang dilaporkan oleh Soelaeman (2008). Dengan demikian mempunyai kemampuan yang sama dalam menghasilkan serapan $P$ jerami seperti yang dilaporkan oleh Lukiwati et al. (2018) dan Ramilison (2001).

Tabel 3. Serapan Nitrogen dan Fosfor Jerami Jagung Manis

\begin{tabular}{lcc}
\hline \multicolumn{1}{c}{ Perlakuan } & $\begin{array}{c}\text { Serapan nitrogen } \\
\text { (g/tanaman) }\end{array}$ & $\begin{array}{c}\text { Serapan fosfor }(\mathrm{g} / \\
\text { tanaman) }\end{array}$ \\
\hline ZA+TSP & $1,31 \pm 0,17^{\mathrm{b}^{*}}$ & $2,80 \pm 2,28$ \\
Pukan sapi+ZA+TSP & $1,62 \pm 0,17^{\mathrm{ab}}$ & $0,73 \pm 0,05$ \\
Pukan kambing+ZA+TSP & $1,50 \pm 0,21^{\mathrm{ab}}$ & $0,67 \pm 0,07$ \\
Pukan ayam+ZA+TSP & $1,75 \pm 0,21^{\mathrm{ab}}$ & $0,83 \pm 0,19$ \\
Pukan sapi plus & $1,45 \pm 0,14^{\mathrm{ab}}$ & $0,36 \pm 0,11$ \\
Pukan kambing plus & $1,91 \pm 0,13^{\mathrm{a}}$ & $0,77 \pm 0,14$ \\
Pukan ayam plus & $1,83 \pm 0,08^{\mathrm{a}}$ & $0,67 \pm 0,15$ \\
\hline
\end{tabular}

* Superskrip berbeda pada kolom yang sama menunjukkan berbeda nyata $5 \%$ dengan DMRT

\section{SIMPULAN}

Pemupukan dengan pukan plus (pukan diperkaya NP-organik) maupun pukan+pupuk anorganik (ZA+TSP) serta pemupukan anorganik (ZA+TSP) memberikan hasil yang sama terhadap berat tongkol berkelobot maupun tanpa kelobot, berat segar dan bahan kering jerami serta serapan $\mathrm{P}$ jerami jagung manis. Pukan plus menghasilkan serapan $\mathrm{N}$ jerami setara dengan pukan+pupuk anorganik. Namun pukan kambing plus dan pukan ayam plus mampu menghasilkan serapan $\mathrm{N}$ jerami lebih tinggi dibanding pemupukan anorganik (ZA+TSP). Pukan plus mampu menggantikan peran pupuk ZA dan TSP sehingga dapat menekan kebergantungan terhadap pupuk anorganik.

\section{UCAPAN TERIMA KASIH}

Dana Penelitian selain APBN Fakultas Peternakan dan Pertanian Undip, Keputusan Rektor Undip No.: 109/UN7.5.5/PP/2018 telah membiayai penelitian ini dan dapat diselesaikan dengan baik. Untuk itu diucapkan terima kasih.

\section{DAFTAR PUSTAKA}

Abdullah, A., H. M. Ali, and J. A. Syamsu. 2015. Status keberlanjutan adopsi teknologi pengolahan limbah ternak sebagai pupuk organik. Mimbar, 31(1): 11-20.

Bhatt, P. S. 2012, Response of sweet corn hybrid to varying plant densities and nitrogen levels, African J. of Agric.Res., 7(46), 6158-6166.

Dierolf T., T. Fairhurst and E. Mutert. 2001. Soil Fertility Kit. A toolkit for acid, upland soil fertility management in Southeast Asia. First edition. Printed by Oxford Graphic Printers. 149 p.

Imran, M., R. Waqas, Z. I. H. Nazli, B. Shaharoona, and M. Arshad. 2011. Effect of recycled and valued-added organic waste on solubilization of rock phosphate in soil and its influence on maize growth. Date of access:11/07/2017. Available: http://www.fspublishers.org/

Lukiwati, D. R. 2002. Effect of rock phosphate and superphosphate fertilizer on the productivity of maize var. Bisma. Proc.of International Workshop Food Security in Nutrient-Stressed Environments: Exploiting Plant's Genetic Capabilities. International Crops Research Institute for Semi-Arid Tropics (ICRISAT) Patancheru, India, 27. Kluwer Academic Publishers. Netherlands. 183-187.

Lukiwati, D. R., F. Kusmiyati, Yafizham, and S. Anwar. 2019. Improvement of plant growth and production of waxy corn with organic-NP enriched manure and inorganic fertilizer in Sragen District of Central Java Indonesia. IOP Conf. Ser.: Earth Environ. Sci. 292: 1-6.

Lukiwati, D. R. dan R. Muryani. 2006. Potensi jerami padi sebagai pakan sapi potong di Kabupaten Rembang. Jurnal Litbang Provinsi Jawa Tengah. 4(1): 7-12.

Lukiwati, D. R. and R. I. Pujaningsih. 2017. Yield performance and nutritive value of sweet corn using manure enriched with agromineral and nitrogen organic. ICONTES Abstract Book. The 3rd Internationa Congress on TechnologyEngineering \& Science. Kuala Lumpur, 9-10 Februari. Abstr. 108.

Lukiwati, D. R., R. I. Pujaningsih, and R. Murwani. 2018. The effect of organic phosphorus and nitrogen enriched manure on nutriive value of sweet corn stover. IOP Conf. Series: Earth and Environmental Science. 119: 1-7.

Lukiwati, D. R., T. W. Agustini, B. A. Kristanto, and Surahmanto. 2010b. Production and nutrient uptake improvement of sweet corn by manure 'plus' combined with inorganic fertilizers. In: Proc. of the $15^{\text {th }}$ World Fertilizer Congress of 
the International Scientific Center for Fertilizers (CIEC). Bucharest, Romania. 29 August - 2 September. pp. 213-219.

Lukiwati, D. R., E. D. Purbajanti, and R. I. Pujaningsih, 2014. Sweet corn production and nutritive value of stover with manure enriched with rock phosphate fertilizer and biodecomposer. J.of Agric. Sci. and Tech. A, 4(10), 839-842.

Lukiwati, D. R., F. Kusmiyati, and B. Herwibowo. 2018. Effect of manure plus and inorganic fertilizer on maize production and nutrient uptake in Central Java Indonesia. Proc.of the 5th International Conference on Agriculture, Colombo. 1:1-6.

Manoharachary, C., Sridhar, R. Singh, A. Adholeya, T.S. Sauryanarayanan, S. Rawa, and B. N. Johri. 2005. Fungal biodiversity, distribution, conservation and prospecting of fungi from India. Current Science. 89(1): 58-71

Qureshi, S. A., A. Rajput, M. Memon, and M. A. Solangi. 2014. Nutrient composition of rock phosphate enriched compost from various organic waste. E3J.of Sci.Res., 2(3), 47-51.

Ramilison, R., 2001, The effect of local rock phosphate fertilizer on yield of maize in P-deficient soils of the Central Plateau of Madagascar. In: Seventh Eastern and Southern Africa Regional Maize Coference. 11-15 February, pp.394-398.

Singh, H, dan M. S. Reddy. 2011. Effect of inoculation with phosphate solubilizing fungus on growth and nutrient uptake of wheat and maize plants fertilized with rock phosphate in alkaline soils. Europen J Soil Biol. 47: 30-39.

Snyder, C. S. and R. H. Leep. 2007. Fertilization. In: Barnes, R.F., C.J. Nelson, K.J. Moore and M. Collins (Eds.) Forages. 6th Edition. Vol. II. Blacwell Publishing. Carlton, Victoria-Australia. pp.355-377.

Soelaeman, Y. 2008. Efektivivtas pupuk kandang dalam meningkatkan ketersediaan fosfat, pertumbuhan dan hasil padi dan jagung pada lahan kering masam. J. Tanah Trop. 13(1): 41-47. Syamsu, J. A., H. M. Ali, M. Ridwan, and M. A. Asja. 2013. Analysis of sustainability status of integration of beef cattle and paddy with technolgoy innovation of rice straw as feed and beef cattle manure as fertilizer and biogas. Environ.and Natural Resources J. 11(2): 1-16.

Widjajanto, D. 2013. Pengaruh pemberian bahan organik daun gamal (Gliricidia sepium) terhadap beberapa karakteristik fisik inseptisols Lembah Palu. J. Sains \& Tek. 15(1): 147-156.

Wireko-Manu, F.D., and Amamoo, C., 2017, Comparative studies on proximate and some mineral composition of selected local rice varieties and imported ric brands in Ghana. Agric. and Food Sci. Res., 4(1), 1-7. 